
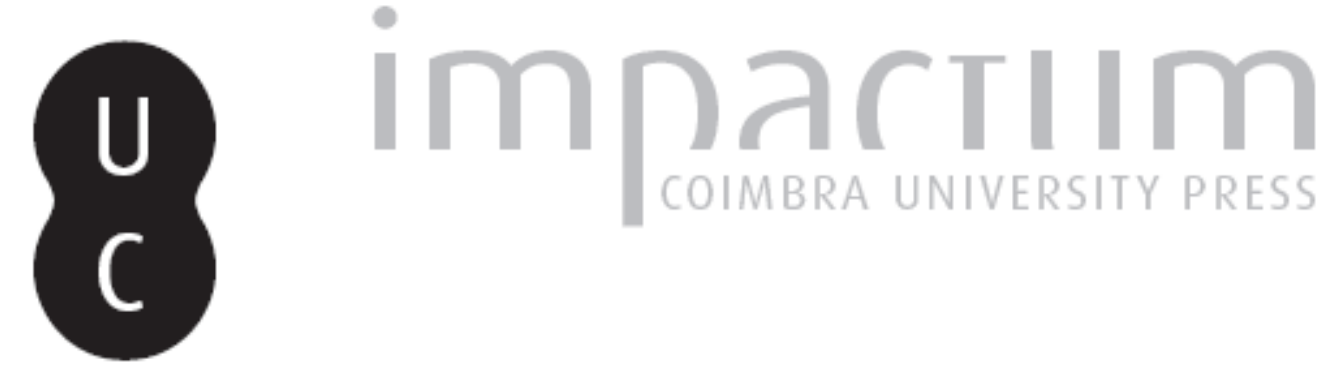

\title{
Uma autobiografia prospectiva do departamento de arquitectura da FCTUC
}

\author{
Autor(es): $\quad$ Krüger, Mário
}

Publicado por: Editorial do Departamento de Arquitectura

URL persistente:

URI:http://hdl.handle.net/10316.2/37433

DOI:

DOI:http://dx.doi.org/10.14195/0874-6168_2_3

Accessed : $\quad$ 26-Apr-2023 08:13:02

A navegação consulta e descarregamento dos títulos inseridos nas Bibliotecas Digitais UC Digitalis, UC Pombalina e UC Impactum, pressupõem a aceitação plena e sem reservas dos Termos e Condições de Uso destas Bibliotecas Digitais, disponíveis em https://digitalis.uc.pt/pt-pt/termos.

Conforme exposto nos referidos Termos e Condições de Uso, o descarregamento de títulos de acesso restrito requer uma licença válida de autorização devendo o utilizador aceder ao(s) documento(s) a partir de um endereço de IP da instituição detentora da supramencionada licença.

Ao utilizador é apenas permitido o descarregamento para uso pessoal, pelo que o emprego do(s) título(s) descarregado(s) para outro fim, designadamente comercial, carece de autorização do respetivo autor ou editor da obra.

Na medida em que todas as obras da UC Digitalis se encontram protegidas pelo Código do Direito de Autor e Direitos Conexos e demais legislação aplicável, toda a cópia, parcial ou total, deste documento, nos casos em que é legalmente admitida, deverá conter ou fazer-se acompanhar por este aviso.

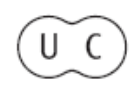




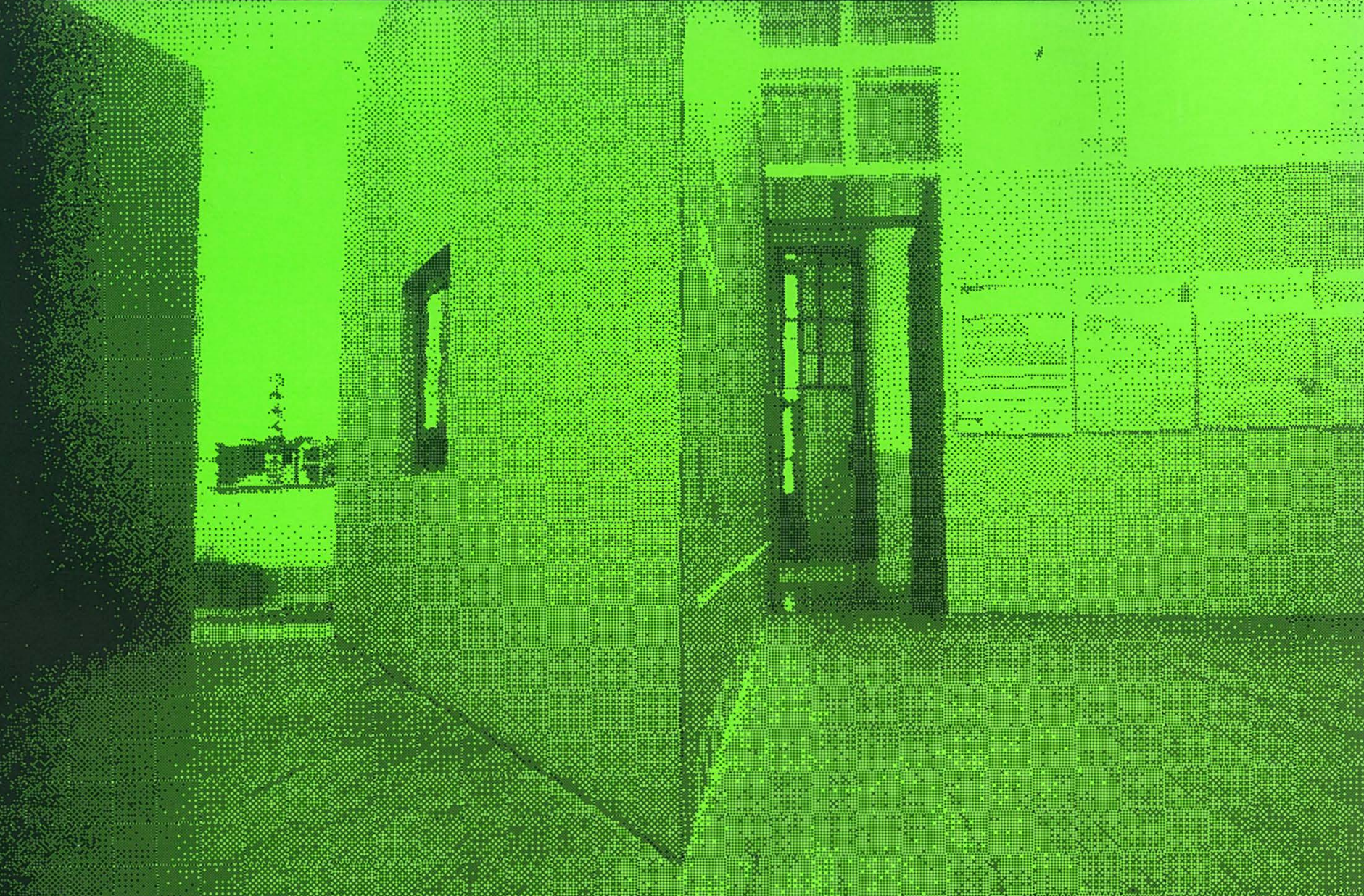

\section{ecdj 2}

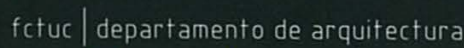

10 anos de arquitectura no colégiodas artes

construir uma escola

tape

encontros de tomar 4

alexandre alves costa vs gonçalo byrne

paulo mendes da rocha 


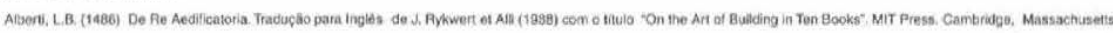
Agosintio, Santo (413-426/427) De civitate Del. Taduçao para Portugu6s. A Citade de Dous. Editora Vozos. Potropolis.

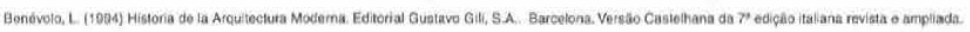

Corvantes. M. de (1616) Domi Quixote. Traduçbo do Castelhano por Albertina de Sousa. Classica Ed tora. 1991. Listoo

Figueira. L. (1999) "Algumas preinissas para um debate" Enoontros de Tomar 4 . Departamento de Arqutectuan. FCTUC Combra.

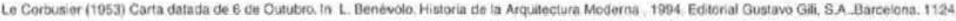

Machel, A. (1998) Paroles de Mai . Luçon

Hykwert, L. Thavenor, A. (1989) Nota 123 ae Liveo DX do De Re Aedicicatoria de LBalbert (1496)

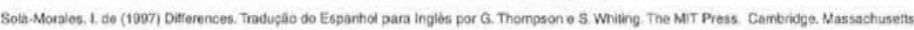

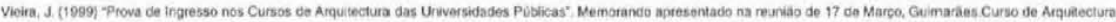

Universidade do Minho.

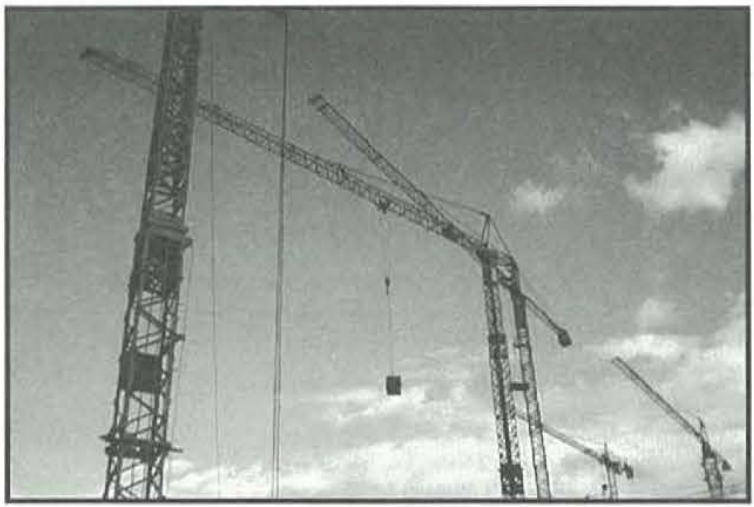

[uma autobiografia prospectiva do departamento de arquitectura da fctuc]

mário krüger

O texto "Algumas premissas para um dia de debate" (Figueira, 1999), elaborado com o objectivo de se lançarem pistas para a discussão de questões relacionadas com as Comemorações dos Dez Anos do Departamento de Arquitectura da FCTUC, a terem lugar no $4^{\circ}$ Encontro de Tomar sugere, entre outros, a discussão de uma prática de ensino e de aprendizagem da arquitectura "que enquadre a natureza e as convenções da disciplina $e$ seja capaz de integrar criticamente a explosão de conceitos e a condição errante da arquitectura contemporânea" 
> Se admitirmos que uma autobiografia é das formas mais elaboradas de fiç̧ão aceitemos esta sugestão $e$ vejamos como temos aderido às convenções, como tem sido a aplicabilidade dos conceitos disciplinares e como se tem processado o nosso nomadismo.

- A licenciatura em Arquitectura da FCTUC foi criada pela Portaria $n^{\circ} 448 / 88$ de 8 Julho e a sua organização curricular alterada por proposta da Comissão Instaladora do Curso de Arquitectura em 28 de Junho de 1990. O Plano de Estudos em vigor, criado legalmente pelo Despacho no $20197 / 98$ (2 $2^{\mathrm{a}}$ Série) de 18 de Novembro, concluíu o conjunto de alteraçōes consideradas necessárias para a adequação dos objectivos, conteúdos e didáticas para uma formação geral no domínio da Arquitectura e especializada no âmbito dos estudos universitários (ver Tabelas 1 e 2).

> O Plano de Estudos tem procurado corresponder ao estabelecido genericamente na Directiva 85/384/CEE sobre o equilíbrio entre os aspectos teóricos e práticos da formação em arquitectura, do desenvolvimento da capacidade para conceber projectos e entender as implicações da sua concretização em construções como do estudo das teorias, história e crítica da arquitectura $e$, ainda, de um razoável conhecimento das artes e das tecnologias que estabelecem inter-faces directas com a área disciplinar.

> Se compararmos globalmente a Portaria n448/88 com o Despacho n² 20 197/88, de agora em diante designados, respectivamente, de Portaria e Despacho, podemos constatar que as suas estruturas curriculares distribuem, diferenciadamente, as disciplinas pelas áreas científicas dos respectivos planos de estudos. Com efeito, na Portaria ocorrem as áreas de Arquitectura, Teoria e História da Arquitectura, Construção, Urbanismo, Matemática e Física a que correspondiam 9 disciplinas exteriores à formação genérica em Arquitectura ministradas por pessoal docente afecto a outras licenciaturas; no Despacho as áreas cientificas contempladas referem-se à Arquitectura, Desenho, Construção, Urbanismo, Matemática e Antropologia a que correspondem 4 disciplinas exteriores à formação em arquitectura, ministradas por pessoal docente de outras licenciaturas e sob a coordenação de outros Departamentos. De 39 unidades de crédito fragmentadas naquelas 9 disciplinas exteriores à formação disciplinar do arquitecto passa-se para 21 unidades de crédito concentradas em 4 disciplinas.

> Se assinalassem que, devido a estas alteraçöes, se verificou um isolamento da Licenciatura em Arquitectura no seio da FCTUC poderiamos responder que não é esse o caso na medida em que soubemos, salutarmente, manter relações com outras áreas disciplinares indispensáveis à formação do arquitecto e promover, simultaneamente, um direcionamento efectivo da licenciatura para o que lhe é essencial. É, por isso, motivo de satisfação o facto de termos em conjunto, alunos e docentes, conseguido estabelecer este ecdj esc.029 percurso ao longo de uma década de peregrinação pela FCTUC.

> Estamos, deste modo, indissoluvelmente ligados na construção da licenciatura em Arquitectura ao que Alberti (1486) considera, noutro contexto, como sendo o "mais importante que se pode obter na arte da construção que é o resultado de saber julgar adequadamente o que é conveniente. Pois que construir resulta de uma necessidade e 
construir convenientemente nasce não só desta necessidade mas sobretudo da sua utilidade.

> Mas construir de modo a que as autoridades dêm a sua aprovação e as pessoas sóbrias não mostrem a sua rejeição resulta unicamente do saber fazer de um artísta douto, prudente e sumamente judicioso".

> Ao comemorarmos a construção da licenciatura em Arquitectura verificam-se, no entanto, novos desafios para adequarmos os saberes disciplinares, transmitidos pelas gerações anteriores, a um mundo que nos coloca perplexidades diversas perante as topografias fluídas do fazer e pensar arquitectonicamente.

> A recombinaçāo e a erosâo acelerada de conceitos disciplinares bem como a secundarização da ponderação sensivel das diferentes partes que compõem as edificações e os seus territórios, da Concinnitas de Alberti, ilustrada por projectos remotos realizados colaborativamente através de video-conferências, da tele-presença e de charretes, onde se constata a diluição de fronteiras entre espaços físicos e disciplinares concretizada, de forma exemplar, pela transformação exclusiva daquela ponderação em impulsos eletrónicos e em tempos de comunicação digital. A agitação e propaganda que algumas escolas de arquitectura fazem quando promovem este tipo de eventos bem como as energias dispendidas na inter-net à busca de um espaço supostamente perdido, onde dificilmente germina a reflexão em acção própria do acto de concepção em arquitectura.

> A estruturação profissional de origem centro-europeia, herdeira das guildas e corporações medievais, presente nas propostas em discussão na Ordem para a regulamentação do acesso à profissão bem como da constituição de colégios de especialidades, subtilmente apoiada pela criação de licenciaturas que, não só, promovem a pulverização de um corpus disciplinar relativamente coeso nos seus fundamentos e autónomo em relaçăo a outras disciplinas, como também, colocam em causa o entendimento da profissāo pela fragmentação do campo total do construir.

> Os não lugares, os espaços virtuais, as cidades invisíveis e as imaginadas conceptualmente que nos fazem ficar na saudade das teorias espaciais de finais do século passado, apesar de termos alternativas credíveis de substituição não assumidas, exemplificada pelo apego a um passado não experienciado ou a um futuro remoto $e$ implausivel.

> As recentes propostas de arquitectura urbana, que se expressam na verticalização excessiva de formas edificadas, tipo XXL, que encontram eco nos debates de La Sarraz e nos CIAM que se lhes seguiram, bem como nos estudos sobre formas construídas que restabeleceram a construção em perímetro como alternativa credivel à realizada em altura. A colisão da figura jurídica do solo criado no regime de propriedade urbana, presente nas cidades norte-americanas como instrumento eficaz de controle da extrema intensidade de uso do solo, com as nossas normas consensuais de direito público, que não deixam de ser, também, um reflexo e uma instância do modo que temos de fazer cidade.

> A multiplicação de concursos públicos de arquitectura que promovem, de forma não 
transparente, a gestão de interesses privados em contra-posiçăo às mais elementares considerações de ética e de deontologia profissional transformando o que era aparente excepção em regra ostensiva.

> Tudo isto lembra que nos encontramos entre uma espécie de "Jardim das Delícias" e as "Tentações de Santo Antão" de Hieronimus Bosch, entre uma idade onde homens e animais viviam em harmonia com a natureza sob o signo do prazer e outra em que os homens "através superação das tentações exteriores podiam aumentar o seu estado de graça" (Agostinho, 413-426/427).

> Em ambos os casos revogam-se, inexoravelmente, os compromissos com uma realidade objectiva em proveito de uma outra, por ventura mais virtual, que se acumulou, recentemente, nos nossos espíritos sob o temor de não pudermos acompanhar a contemporaneidade, colocando em risco a promoção de um saber que se tem pautado pela elaboração, de forma reflexiva, de princípios ou regras generativas que têm permitido a criação efectiva de espaços construídos com qualidade.

> Por muito incongruentes que sejam as associações de ideias que possamos encontrar nos quadros de Bosh a que fizemos referência as mesmas sugerem, no entanto, uma correlação entre uma lógica do absurdo e as perplexidades acima apontadas.

> No futuro, os novelistas ou, talvez mesmo, os ensaístas poderão acompanhar o desenvolvimento desta incessante renovação para narrar o que estas novas realidades provocaram ou exigiram de colaboração interpretativa para quem as vê ou lhes sofre, inadevertidamente, os efeitos. Até lá, nestas horas ainda louras, retornemos o nosso olhar para a Licenciatura em Arquitectura da FCTUC.

> Consideremos, a propósito da estruturação curricular, a Directiva 85/384/CEE e a maneira como é sugerida a organização dos planos de estudos em arquitectura. Das onze alíneas que compõem o articulado relativo a esta formação é dada, justamente, importância capital à formação de troncos verticais nas áreas disciplinares da Arquitectura omitindo-se, praticamente, a possível interrelação entre as mesmas. A única referência explícita ao relacionamento de saberes ocorre no parágrafo 5 do Artigo $3^{\circ}$ que indica a aquisiçăo "da capacidade para apreender as relações, entre, por um lado, o homem e as criações arquitectónicas e, por outro, as criações arquitectónicas e o seu ambiente, bem como a necessidade de relacionar entre si criações arquitectónicas e espaços em função das necessidades e da escala humana". Esta constatação, demasiado genérica, apresenta, no entanto, o mérito de chamar a atenção para a importância de interrelacionar saberes e áreas distintas de conhecimento no domínio da formação em Arquitectura.

> Das seis áreas científicas existentes no Plano de Estudos em vigor podemos verificar que ecd j 080.031 as possibilidades de interrelacionamento entre as mesmas são vastas. No Diagrama, onde se representam esquemáticamente estas relações podemos observar que na base do mesmo temos um conjunto vazio e no topo as seis áreas agrupadas (A - Arquitectura, D Desenho, C - Construção, U - Urbanismo, M - Matemática e An - Antropologia) correspondendo aquele primeiro conjunto à ausência de interrelações entre as áreas e o 
segundo à representação simultânea de todas as relações entre áreas como sucede, normalmente, nos Encontros de Tomar.

> Entre estas duas possibilidades extremas ocorrem situaçōes intermédias, desde cada área se relacionar isoladamente com uma outra qualquer, e assim sucessivamente, até termos as seis áreas de conhecimento interrelacionadas de forma conjunta (ver Fio.11.

> Das 15 possíveis relações entre as áreas quando consideradas duas a duas somente se verificam interrelacionamentos curriculares entre três: Arquitectura, Construção e Urbanismo, isto é, somente cerca de $20 \%$ da capacidade para interrelacionar conhecimentos, práticas e saberes ocorre, de alguma forma, no normal funcionamento do ano escolar. Das 192 possibilidades de cruzamentos e fertilizações recíprocas entre todas as áreas consideradas isoladamente, duas a duas, três a três e etc. até chegarmos ao conjunto completo de interrelaçōes somente são cobertas 9 interrelações dadas pelas mesmas áreas anteriormente referidas o que corresponde a $4,68 \%$ das possíveis interacções entre áreas ${ }^{\text {(ropresentadas por lanhas azuis na fig. 2) }}$. Mesmo se tirássemos as interrelações entre áreas que não dizem respeito directamente à Arquitectura, como é o caso da Antropologia e da Matemática e das situações onde ambas ocorrem maioritariamente, (representacas a vermetho na Fig 2) ainda teriamos, de um total de 186 relações possiveis, somente 9 realizadas no actual modo de funcionamento do plano curricular.

> Estas constatações sugerem que, a fim de podermos colocar em pleno funcionamento o Plano de Estudos em vigor, teremos de explorar atentamente os cruzamentos e as fertilizações recíprocas passiveis de potenciar e enriquecer a respectiva organização curricular. Tarefa esta que não é fácil de ser executada mas passivel de implementação gradual se as áreas se começarem a interrelacionar com objectivos comuns e propósitos bem definidos. Isto é possível de ocorrer em diversas instâncias, nomeadamente no âmbito dos trabalhos que venham a ser desenvolvidos para o Centro de Estudos de Arquitectura, actualmente em fase de implementação.

> Pela primeira vez, desde a sua existência, o Departamento de Arquitectura foi contemplado com um financiamento pluri-anual para o funcionamento do seu Centro de Estudos o que irá permitir desenvolver, desde já, algumas acções, quer no âmbito de respostas a encomendas quer numa gestão conjunta de recursos físicos e humanos com o próprio Departamento. Para já, uma certeza: as encomendas dirigem-se, maioritariamente, para aquilo que no âmbito das unidades de I\&D é considerado desenvolvimento: reorganização do Museu de Arte Sacra e da Capela de S. Miguel, programa do Concurso para o Colégio da Graça e o Estudo Histórico e Tipológico da Rua da Sofia e Área Envolvente encomendados pela Vice-reitoria da Universidade de Coimbra bem como, possivelmente, o estudo e a organização de uma exposição sobre o Convento de Sta. Cruz a ser promovida pela Câmara Municipal de Coimbra.

De acordo com as recomendações do orgão financiador, a Fundação para a Ciência e 
Tecnologia, o principal aspecto a ser contemplado e que justifica, em parte, o financiamento pluri-anual que nos foi atribuído refere-se mais a acções de investigação e menos às de desenvolvimento. Sabemos que, na área de Arquitectura, esta distinção é, na maior das partes das vezes, desprovida de significado. Em outras áreas de conhecimento produz-se investigação de natureza fundamental o que sugere, já que estamos na Universidade, que tenhamos a disposição para fazer este tipo de investigação. No entanto, não conseguimos concebê-la como tal na medida em que não sabemos exactamente o que isso pode significar em arquitectura. Consideramos que a mesma deverá, pelo menos, transformar o aparentemente inexplicável em resultado previsível no âmbito disciplinar. Assumir, com alguma modéstia e rigor, este caminho parece-nos ser, também, o passo a dar neste momento de lançamento do Centro de Estudos.

> Cabe a este novo Centro servir de suporte para acções de formação e extensão no âmbito da Prova Final e dos cursos de Pós-graduação que venham a ser criados.

> Aquela Prova tem-se pautado por ser o coroamento da Licenciatura em Arquitectura da FCTUC podendo revestir um carácter teórico, prático ou teórico-prático.

> No entanto, a mesma tem-se revelado, desde a sua implementação, tanto um factor de qualificação do corpo discente como de estrangulamento devido à relativamente baixa percentagem de alunos que concluem a Licenciatura quando comparados com o número de total de alunos regularmente matriculados ou com o número de alunos que frequentam, pela primeira vez, o primeiro ano da Licenciatura ${ }^{\left(v e r F_{0} .3\right)}$.

- Desde 1995, ano em que saíu a primeira turma de licenciados, as percentagens de alunos que concluíram o curso relativamente ao número de alunos inscritos no $1^{\circ} \mathrm{Ano}$, pela primeira vez, foram as constantes na Tabela 3.

- Por outras palavras, nunca o número de alunos licenciados chegou a ultrapassar $26,5 \%$ do número de alunos que entraram, desde aquela data, regularmente pela primeira vez para o primeiro ano. Apesar de a figura de Seminário ter sido, recentemente, introduzida como forma priveligiada de promover a orientação da Prova Final para corrigir esta situação não se têm notado alterações substanciais em relação às tendências anteriormente verificadas.

> Para isto tem contribuido o facto de as Provas Finais incidirem, quase exclusivamente, sobre temas teóricos que conduzem a um arraste excessivo do tempo de duração previsto para a sua conclusão bem como a Prova ser ponderada, mais do que proporcionalmente, quando comparada com as restantes disciplinas do Plano de Estudos, o que conduz a um investimento excessivo de tempo por parte do aluno para a sua conclusão na plausibilidade que será recompensado pelo seu esforço aumentando, assim, a média de curso. Não nos enganemos, entretanto, por aqueles números ou por esta situação de estrangulamento.

> Conforme foi transmitido por diversos membros da direcção da actual Ordem dos Arquitectos o que tem distinguido o curso de Arquitectura da Universidade de Coimbra tem 
sido a sua excelência pautada por um rigor de procedimento o que é fundamental para podermos crescer junto a Departamentos e Cursos com muito maiores tradições científicas e provas dadas do que as nossas. Aquela avaliação é, no entanto, parcial na medida em que corresponde a opiniões formadas que não se baseiam numa análise sistematizada das condições de funcionamento da licenciatura.

> Lembremo-nos, a propósito, que foi lançado no ano passado um inquérito dirigido aos alunos de forma a complementarmos a Auto-avaliação do curso exigida pela Fundação das Universidades Portuguesas. Tivemos a preocupação de não elucidar a que se destinava o inquérito para não enviesar as respostas dadas e obtivemos um resultado globalmente favorável em relação à maneira como os alunos avaliaram a licenciatura em Arquitectura. No próximo mês de Junho será realizada a visita da Comissão de Avaliação Externa e aí poderemos, talvez, obter subsídios para uma apreciação mais sistematizada do que a que temos tido até aqui.

> Subsiste, no entanto, o que fazer com a Prova Final não só face ao estrangulamento constatado como às novas exigências profissionais de acesso à Ordem dos Arquitectos, actualmente em fase de discussão.

> A Comissão Científica do DARQ aprovou recentemente que se propusesse à Ordem a contagem da Prova Final como sendo equivalente a um ano de estágio profissional colocando como contrapartida o convite para que aquela se fizesse representar nos Jurís das provas com o estatuto de observador. Apesar de não sabermos, ainda, a resposta conjecturamos, face ao que nos foi transmitido pelo Presidente da Seç̧ão Regional do Norte da OA, que a duração do estágio, a ser futuramente implementado, não deverá ultrapassar, como tempo mínimo, seis meses o que inviabilizará, na prática, a proposta anteriormente feita.

> Acrescente-se, ainda, que o Conselho Directivo da OA em resolução de 20 de Fevereiro de 1999 resolveu que os licenciados pelos cursos cujas licenciaturas eram aceites pela AAP à data da entrada em vigor do Estatuto da Ordem continuavam a ser aceites pelo prazo de dois anos com os mesmos direitos e prorrogativas, correspondendo na prática à aceitação da Inscrição na Ordem, durante este período, dos licenciados em Arquitectura pela FCTUC.

> Este modelo de acesso à organização que regula a profissão, que designamos De Jure

> (De Facto), necessita de ser alterado e ajustado às novas contigências, quer sejam profissionais quer académicas, mas sem perda ou mesmo com aumento de qualidade curricular, para nos podermos convenientemente posicionar não só em relação a outras licenciaturas da FCTUC como a outras escolas de arquitectura ${ }^{\text {(ver Fig. 4). }}$.

Existem, pelo menos, três possibilidades que alteram a configuração das saídas profissionais e académicas dos alunos da licenciatura. Correspondem aos modelos Nil Novi Sub Sole (Nada de Novo sob o Sol), More Majorum (De acordo com os nossos Maiores) e Mutatis Mutandis (Mudando o que tem de Ser Mudado).

> No modelo Nil Novi Sub Sole (ver Fig-4) nada se modifica em relação à organização curricular 
do Plano de Estudos apesar de ocorrerem alterações substanciais em relação ao acesso à profissão pela obrigatoriedade da realização do Estágio. No More Majorum ${ }^{\text {(vor Fig. } 5\}}$ o acesso à profissão é idêntico ao anterior, isto é, após a realização da Prova Final o aluno pode inscrever-se no Estágio Profissional para acesso à Ordem e, ainda, em cursos de pósgraduação que venham a ser abertos no âmbito das especializações e mestrados do DARQ. Finalmente, no Mutatis Mutandis ${ }^{\text {(ver Fig. 6) }}$ a saída da licenciatura ocorre sem a realização da Prova Final, como a conhecemos, podendo o aluno inscrever-se, imediatamente, no estágio profissional ou em cursos de pós-graduação.

> Qualquer destas três últimas opções apresentam vantagens e desvantagens que têm de ser devidamente ponderadas.

- O modelo Mutatis Mutandis implica, necessariamente, um ajuste no Plano de Estudos na medida em que a Directiva $85 / 384 / \mathrm{CEE}$ (Artigo $4^{\circ}$, parágrafo $1^{\circ}$, alínea b) estipula que a "formação deve ser concluída pela aprovação num exame de nível universitário". Isto significa que estamos implicitamente a assumir que esse exame ocorra no final do $5^{\circ}$ Ano da licenciatura o que obrigará, na prática, a uma redução dos tempos do ano lectivo como temos praticado até agora. Será que isso é compatível com o nivel de qualidade pelo qual este curso se tem pautado desde sempre?

> O modelo More Majorum sugere que se mantenha a Prova Final para conclusão da licenciatura. Podemos dizer que é, certamente, um acréscimo de esforço, em relação à situação presente, para quem pretende inscrever-se na Ordem, após a conclusão da Licenciatura, pela obrigatoriedade do Estágio. Em contrapartida, podemos argumentar que, se a Prova Final e o Estágio Profissional forem, cada um, realizados no prazo previsto de seis meses, pouco se altera em relação ao tempo dispendido actualmente para a realização da Prova Final. Isto sugere que, a ser aprovado este modelo, teremos de modificar os conteúdos, essencialmente teóricos, para outros tipos de trabalhos que não exijam o mesmo investimento de tempo. Isto sugere que os trabalhos da Prova Final se coloquem, para não perderem qualidade, a título meramente exemplificativo, no seguimento do tronco das disciplinas de Projecto e Construção que percorrem o curso do $1^{2}$ ao $5^{\circ}$ ano. Neste caso, a Prova Final poderá ser entendida como a continuação conclusiva deste percurso - levado a cabo de um modo talvez mais reflexivo - e ao qual as disciplinas de Projecto dos últimos anos da licenciatura se teriam de ajustar para dar a possibilidade da sua resolução efectiva.

> Por último, no modelo Nil Novi Sub Sole apesar de o nome sugerir que nada se altera tudo muda em relação ao esforço dispendido pelos alunos que continuarão a realizar uma Prova Final nos moldes actuais com um forte investimento de tempo para além do Estágio Profissional que venha a ser aprovado pela Ordem. Resta, neste modelo, sugerir a redução do número de anos lectivos da licenciatura o que está fora de questão se quisermos atender ao proposto pelo Comitê Consultivo para a Formação no Domínio da Arquitectura que, na Recomendação sobre "A duração dos estudos de arquitectura" de 14/03/1990, 


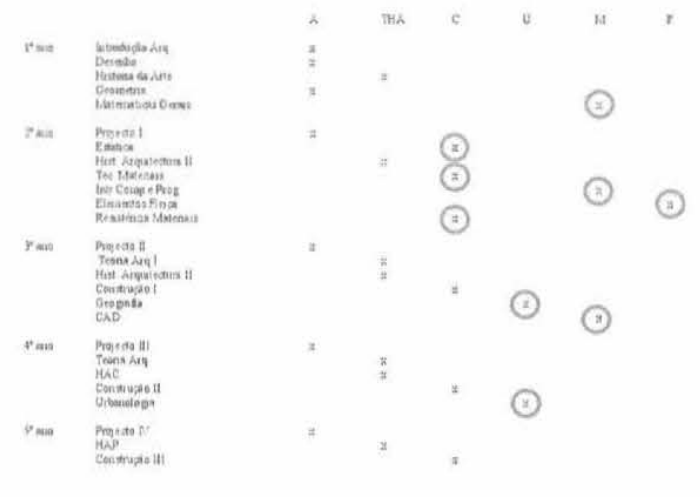

Tabela 1. Relaphes ontre dreas o Disciplinas cadas pela Portaria n" 44898 de 8 do Julho allerada pots proposta da Comissaio Insta adora do Curso de Arguitectura em 28 de Junto de 1960. Os circulas assinatarn discipinas ederiores a tormaçato en Arquitectura.

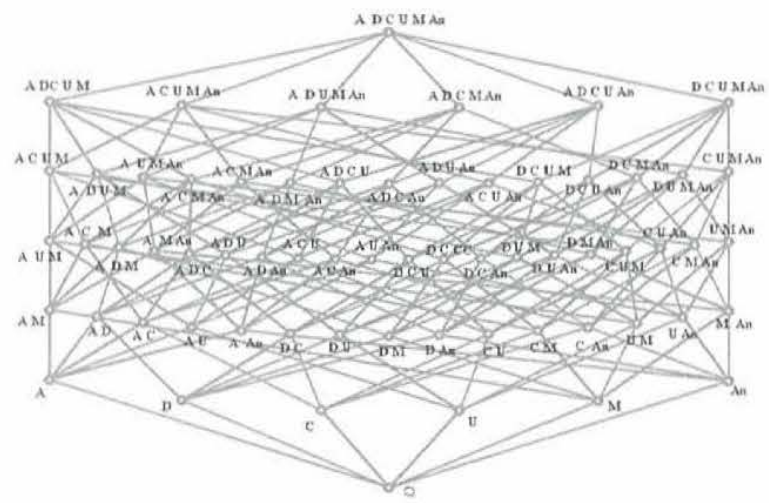

Fiq 1. Diagrama de hiterrelapbes possiveis entre ns seis ateas cientilicas que conpdem o actual Piano do

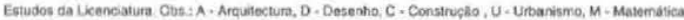
- An - Antropologa.

Ano $\mathrm{N}^{*}$ Alunos Licenciados $\quad \mathrm{N}^{*}$ Alunos Inscritos no $\mathrm{I}^{*}$ Ano Percentagen

\begin{tabular}{llll} 
& & pela 1'vez & (०) \\
\hline 1995 & 13 & 55 & 23 \\
1996 & 6 & 48 & 12,5 \\
1997 & 13 & 49 & 26,5 \\
1998 & 16 & 69 & 23,2
\end{tabular}

Tabeta 3. Percentagem do Nümero de Nunos Licenciajos por Nümero de Alunos insertilos no 1 " Ano peta Primeira Vex durante os anos de 1905 a 1998 . Fonte: Dados tornecidos pelos Servicos Academicos da Universidade de Coimbra

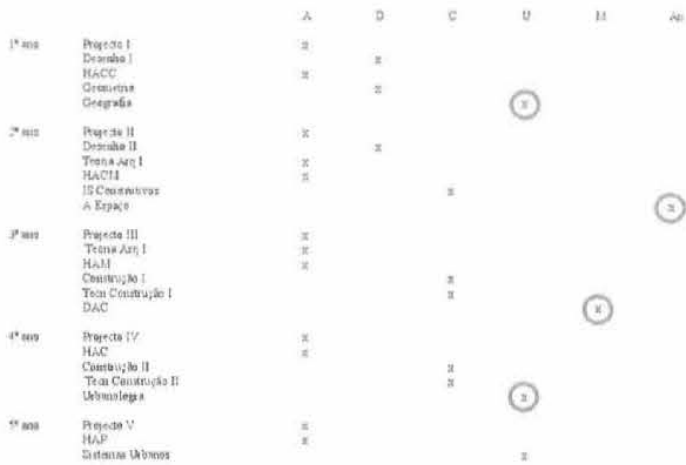

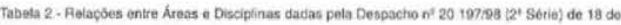

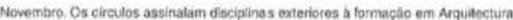

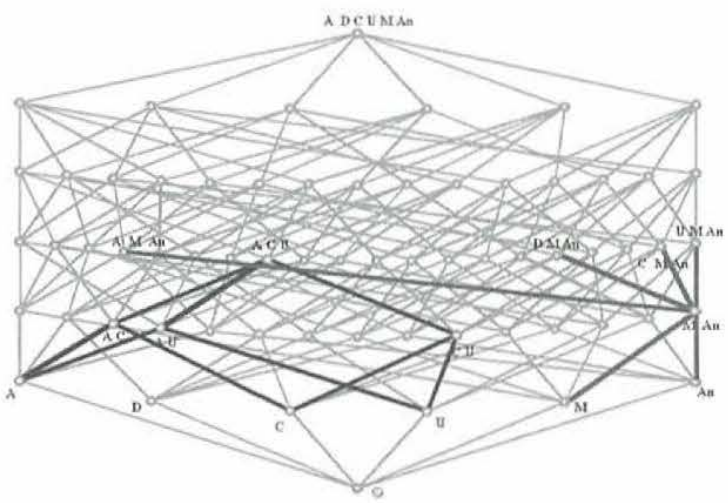

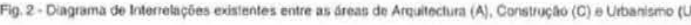
(assinaladas a azu) e das äteas extra-disciplinares de Masematica (M) e Antropologia (An) (assinaladas a vernelho,

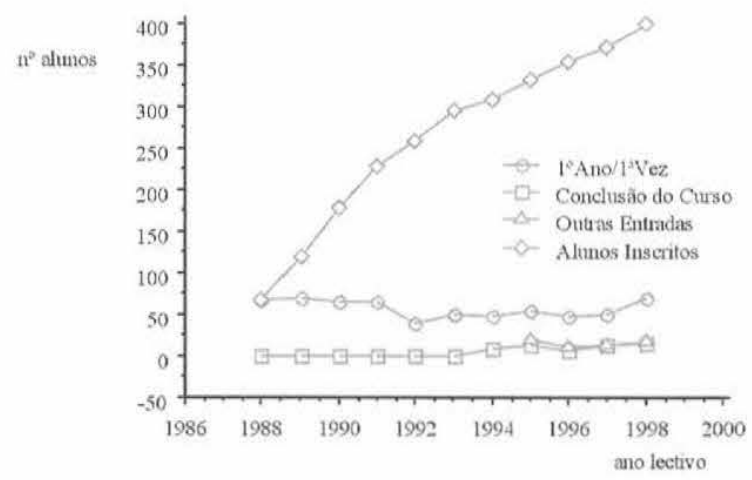

Fig. 3. Frequência de Alunos do DARO-FCTUC 1938-1993. Fone: Sorvogos Académicos da UC 

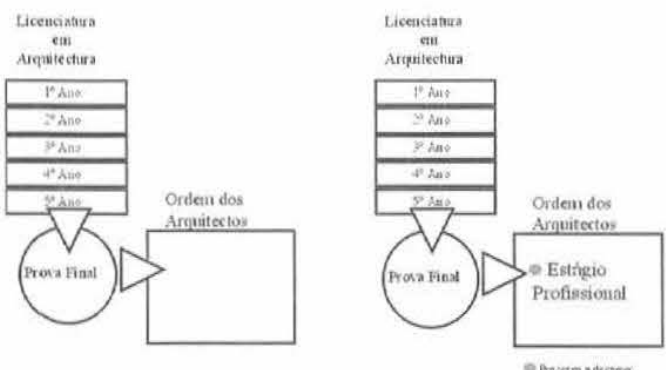

Fig 4- Modelos de Desenvolimento De vure o Ni Novi Sub Saio

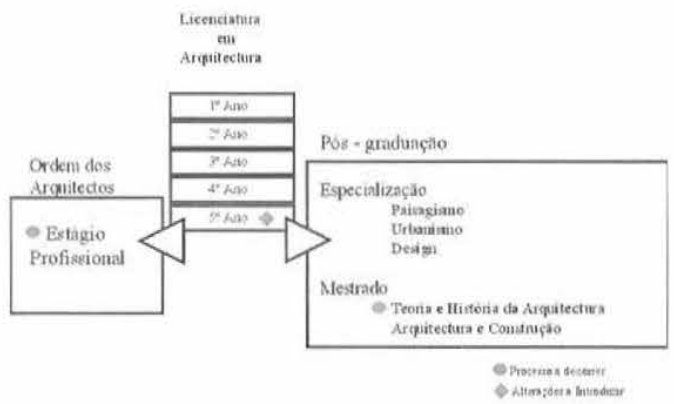

Fig, 6- Modelo do Desenvolvimento Mutatis Mutandis.

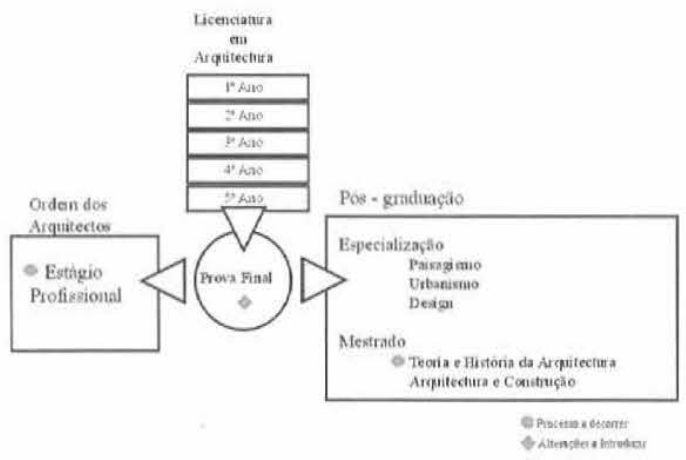

Fig. 5. Mocelo de Desernoivmento More Majorum.
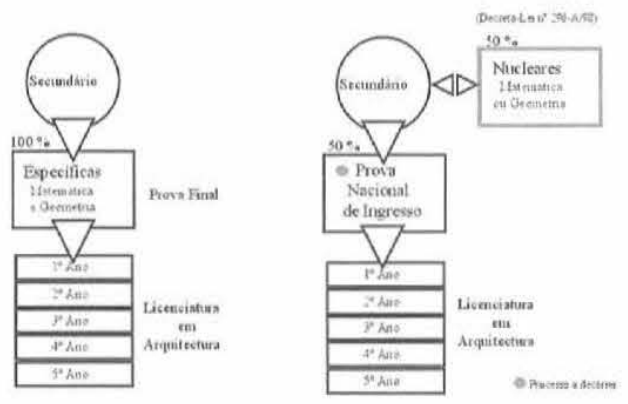

Tabeia 4- Dados do Acesso a Licenoiatura em Arquiliectura do DARQ-FCTUC em 1997 e 1898

\begin{tabular}{|c|c|c|c|c|c|c|c|c|c|c|}
\hline \multicolumn{2}{|c|}{ Ofeeta } & \multicolumn{4}{|c|}{ Proctua } & \multicolumn{5}{|c|}{ Valor des Colocados } \\
\hline Ano & Vagas & Cand & datos & $\mathrm{Col}$ & cados & Nota & Me. & as dor & Colocadk & \\
\hline & & Texi & $P \mathrm{Cosin}_{0}$ & Tous & Pows & wh cat & Itens & $D E$ & is & $1{ }^{\circ}$ \\
\hline 1997 & is & 496 & is & is & 1: & 3630 & 1654 & $17: 5$ & 1533 & 1597 \\
\hline $19 \%$ & 56 & a) & 92 & 30 & 3 & 1641 & $m 3$ & 174 & 1652 & 1632 \\
\hline wiver & as) & +4 & +35 & +43 & +108 & +16 & ts? & & & \\
\hline
\end{tabular}

Tabela 4-Dados do Acesso a Licenciatura em Aiquiectura do DARQ-FCTUC en 1997 o 1928

\begin{tabular}{|c|c|c|c|c|c|c|c|c|c|c|}
\hline \multicolumn{2}{|c|}{ Oferta } & \multicolumn{4}{|c|}{ Procura } & \multicolumn{5}{|c|}{ Valor dos Colocallor } \\
\hline \multirow[t]{2}{*}{ Ane } & \multirow[t]{2}{*}{ Vhapat } & \multirow{2}{*}{\multicolumn{2}{|c|}{$\begin{array}{l}\text { Cradidator } \\
\text { Taul progle }\end{array}$}} & \multirow{2}{*}{\multicolumn{2}{|c|}{$\begin{array}{l}\text { Colocados } \\
\text { Tein ropese }\end{array}$}} & \multirow{2}{*}{$\begin{array}{l}\text { Nota } \\
\text { wi cit }\end{array}$} & \multicolumn{2}{|c|}{ Médias dor } & \multicolumn{2}{|l|}{ Colocados } \\
\hline & & & & & & & Hots & DE & 12 & it \\
\hline 1397 & 100 & $m$ & 15) & 100 & *o & 3406 & $15: 3$ & 151: & 1586 & $\{929$ \\
\hline is9s & 160 & 659 & 161 & 100 & $\eta$ & 1490 & 163: & 1682 & 15ss & 1800 \\
\hline$\therefore \mathrm{Vu}$ & 0 & 11 & +1 & 4 & +18 & +20 & +10 & & & \\
\hline
\end{tabular}

Tabea 6 - Dados do Acesso a Licenciatura em Natematica de FCTUC em 1997 e 1998 
sugere que:

> a) A duração mínima dos estudos seja pelo menos de cinco anos, os quais deverão ser completados por dois anos de experiência e formação prática;

> b) Nos casos em que a formação tiver seis anos de duração e incluir um ano de formação prática apenas deverá ser complementada por um ano de experiência e formação prática.

> A única alternativa será, assim, introduzir em seis anos de formação um ano de experiência prática o que, no contexto actual, se apresenta de realização problemática pelas dificuldades, já detectadas pela Ordem dos Arquitectos, em implementar o Estágio Profissional.

> Resta, quanto a nós, escolher judiciosamente entre o modelo Mutatis Mutandis e o More Majorum atendendo a que não é desejável que ocorra perda de qualidade na formação dos alunos que concluem a licenciatura nem que os mesmos fiquem sujeitos a um substancial acréscimo de esforço e de tempo para poderem se inscrever na organização que regula a profissão.

> Ao apresentarmos estes modelos sugerimos, implicitamente, a possibilidade de os alunos que concluem a licenciatura em Arquitectura da FCTUC poderem inscrever-se em cursos de pós-graduação.

> Com efeito, está em estudo a organização de um Mestrado em Teoria e História da Arquitectura e conjectura-se o lançamento, logo que as condições o possibilitem pela qualificação progressiva do corpo docente do DARQ, de outro mestrado na área de Arquitectura e Construção. O objectivo do primeiro é contribuir para a sólida formação de investigadores que, nas áreas de Teoria, Crítica e História da Arquitectura, possam preencher uma lacuna no espaço de intervençăo cultural que estas disciplinas sugerem. Isto significa que a produção de investigação se materialize ao nivel de monografias como de dissertações e teses o que entrará em confronto, inevitalvemente, com os conteúdos e métodos da Prova Final como a conhecemos - só com uma diferença, e esta substancial os alunos que frequentarem este mestrado terăo formação específica escolar quase que exclusivamente orientada para aquela produção ao contrário do que ocorre maioritariamente hoje com os alunos que realizam esta Prova.

> Subjacente à criação de Mestrados e/ou de outras pós-graduações que venham a ser pensadas - nomeadamente nas áreas do Design, Paisagismo e/ou Urbanismo que são as mais comentadas actualmente - coloca-se a questão de sabermos claramente se vamos manter a dimensão da licenciatura com o número aproximado de alunos que a frequentam e crescer noutras direcções ou se vamos expandir tanto num nível como noutro de ensino.

> As opçōes, quanto a nós, terão de ser claras. Não expandir na licenciatura significa, possivelmente, o congelamento da dimensão do corpo docente dado o modelo de dimensionamento do ensino universitário estar indissoluvelmente ligado ao Número de Alunos Equivalente em Tempo Integral. Por outro lado, apostar na expansão pelo crescimento da Pós-graduação significa aumentar as possibilidades de formação e de qualificação do futuro pessoal docente que poderá ir preencher lugares em novos cursos 
ou licenciaturas que se cogitem para o crescimento horizontal do Departamento apostando aqui, muito claramente, na posição assumida recentemente pelo Magnífico Reitor ao declarar que o Departamento ainda não era uma Faculdade.

> Até lá teremos de promover, de forma continuada e crítica, o justae nuptiae in tempore opportuno - o casamento justo no tempo certo, que foi o que fizemos na reestruturação da licenciatura em Arquitectura levada a cabo ao longo dos últimos dez anos, que acabou por se distinguir disciplinarmente das outras existentes na FCTUC pela importância que as disciplinas ministradas no Departamento dão à reflexão em acção fazendo com que a contribuição do ensino da Arquitectura no contexto da Universidade de Coimbra seja única. Com efeito, as disciplinas da área de arquitectura em geral e de projecto em particular representam uma forma de ensino que tem por objectivo produzir algo a ser construído implicando um envolvimento com materiais concretos que irão ser moldados e formatados em relação a resultados desejados. Esta especificidade define um campo disciplinar próprio como fundamenta, academicamente, a transformação do actual Departamento de Arquitectura numa Faculdade desde que aquele cresça com sentido e propósito. Promover um ensino de licenciatura de elevado nível ao mesmo tempo que lançamos a pós-graduação é, de forma inequivoca, a estratégia a seguir desde que esta acabe por promover o fortalecimento daquela.

> No entanto, algumas dúvidas ainda subsistem em relação ao modo de funcionamento do presente Plano de Estudos, principalmente quando constatamos que, no elenco das disciplinas que concorriam anteriormente para a formação curricular está ausente a Matemática sendo a mesma contemplada, no entanto, como prova específica de avaliação para preenchimento de vagas. Argumentou-se, na revisão curricular, que os conhecimentos que os alunos traziam do ensino secundário eram suficientes para satisfazer as exigências curriculares do novo Plano de Estudos.

> Lembremos que, para Alberti (op.cit.), "as disciplinas que têm a ver com o arquitecto, ou antes, que são absolutamente imprescindiveis, são a pintura e as matemáticas. Não estou preocupado se for entendido nas restantes. Na verdade, não vou dar ouvidos a quem afirme que o arquitecto deve ser pessoa entendida em leis, pelo facto de que no decorrer do seu trabalho tenha de saber a legislação relativa ao depósito de águas, ao estabelecimento dos limites de propriedade ou ao anúncio público das obras. Nem peço que tenha um conhecimento perfeito de astronomia, pelo facto de ser conveniente construir as bibliotecas orientadas a norte e os banhos públicos a poente. Nem vou afirmar que deve ser músico pelo facto de que se utilizam vasos de ressonância nos teatros; ou orador para dialogar com o seu cliente sobre aquilo que se propõe fazer. Bastará tratar os temas com ponderação, experiência, sabedoria e deligência nos assuntos a serem discutidos para que fale de forma articulada, precisa e informada e que são precisamente as de maior importância na oratória. Contudo, não deve ser desarticulado nem insensivel ao som da harmonia; é suficiente que não construa em terreno público ou na propriedade de outra pessoa; que não obstrua a luz; que não transgrida os regimes de servidão relacionados 
com a queda das águas excepto nos casos de direito de passagem; bastará que conheça o regime de ventos, a sua direcção e os seus nomes; no entanto, não o criticarei se tiver uma formação melhor. Contudo, não Ihe será possivel ter insuficiências nos conhecimentos de pintura e matemáticas assim como ao poeta em relação à entonação de voz e ao conhecimento da métrica. Nem penso que um conhecimento limitado daquelas matérias seja suficiente".

> Será que o discurso de Alberti ainda faz sentido nas condições de hoje para a licenciatura em Arquitectura da FCTUC, passados mais de quinhentos anos desde a altura em que colocou que a pintura e as matemáticas são essenciais para a formação do arquitecto ?

> Se a pintura comparece de alguma forma, na estrutura curricular do curso através das disciplinas de Desenho I e II a mesma tem estado ausente do processo de aferição para entrada na licenciatura e, quase vice-versa, para as matemáticas que comparecem nas provas para admissão através das disciplinas de Matemática e Geometria Descritiva enquanto no Plano de Estudos em vigor somente podemos constatar a ocorrência da Geometria.

> Reparemos, a este propósito, nas classificaçöes e condições de acesso à licenciatura em Arquitectura da FCTUC nos últimos dois anos, isto é, em 1997 e 1998. Na Tabela 4 podemos verificar que para um elevado número total de candidatos que concorreram somente $15,8 \%$ e $20,6 \%$ escolheram a licenciatura em arquitectura do DARQ-FCTUC como primeira opção. Dos alunos que foram, efectivamente, colocados essas percentagens sofreram um acréscimo para, respectivamente, 34,3\% e $50 \%$. Em qualquer dos casos e na melhor das hipóteses somente $50 \%$ dos alunos colocados escolheram, como primeira opção, a licenciatura em arquitectura do DARQ-FCTUC

> Se verificarmos, agora, as médias dos colocados e compararmos a média da Nota de acesso, com as clasificaçōes médias obtidas no $11^{\circ}$ e $12^{\circ}$ anos constatamos que aquela Nota sobe, nos anos de 1997 e 1998, cerca de, respectivamente, 0,7 e 0,8 e que, por outro lado, a Nota do último colocado se mantem praticamente inalterável apesar do número de vagas ter aumentado, de um ano para outro, de 35 para 50.

> Isto significa que, por um lado, não estamos conseguindo colocar a maioria dos alunos que escolhem a licenciatura em arquitectura do DARQ-FCTUC como sendo uma $1^{\circ}$ opção o que se traduz num desajuste entre as aspirações dos candidatos e, possivelmente, a sua vocaçâo por arquitectura e a sua perferência por Coimbra e, por outro, as provas específicas, que não contemplam a pintura mas somente as matemáticas, pouco diferenciarem em relação às médias do ensino secundário.

> Reparemos, agora, o que se passa com as condições de acesso à licenciatura da FAUP

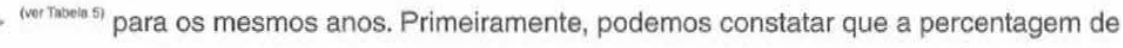
alunos colocados que escolheram arquitectura como $1^{\text {a }}$ opção em relação ao total de colocados foi de, respectivamente, $93,7 \%$ e $95,8 \%$ e que a média da Nota de acesso quando comparada com as médias do $11^{\circ}$ e $12^{\circ}$ ano sofreu um acréscimo de 1,1 valores 
sendo que as notas dos últimos alunos colocados foram aproximadamente iguais $(17,75$ para 1997 e 17,79 para 1998) apesar do número de vagas ter diminuido de 150 para 120.

$>$ As condições de acesso à licenciatura da FAUP, quando comparadas com as do DARQFCTUC, mostram que aquela não só consegue receber uma grande maioria de alunos que escolhem arquitectura e esta escola como primeira opção como o processo de seleção se revela, aparentemente, mais adequado na medida em que consegue diferenciar melhor as classificaçōes obtidas no ensino secundário apresentando, ainda, variação semelhante quando comparamos a classificação do último colocado em relação às flutuações dos números de vagas.

> Isto sugere que a diferença reside, também, nas disciplinas especificas de exame de acesso que na FAUP são Matemática ou Geometria Descritiva e no DARQ-FCTUC são Matemática e Geometria Descritiva.

> Isto fica mais evidente se compararmos estes resultados, para os mesmos anos, em relação à licenciatura em Matemática da FCTUC (ver Tabota e) . Primeiramente, repare-se que os alunos colocados que escolheram Matemática e a FCTUC como primeira opção, quando comparados com o total de alunos colocados, foram, respectivamente, de $60 \%$ e $71 \%$ para aqueles anos. Atente-se que a Nota do último colocado foi de, para estes anos, 14,0 e 14,9 e que a média dos colocados quando comparada com as médias do $11^{\circ} \mathrm{e} 12^{\circ}$ ano decresceu em cerca de 0,2 para 1997 e aumentou 0,5 para 1998.

> Isto sugere que os alunos que entraram para a licenciatura em Arquitectura da FCTUC estão, à partida, melhor preparados para cursarem a licenciatura em Matemática da FCTUC do que a maioria dos alunos colocados e que escolheram esta licenciatura como primeira opção. Que a maioria dos alunos colocados e que escolhe Matemática como $1^{\text {an }}$ opção não é penalizada por esta escolha e que, por último, a Matemática como prova específica pouco altera a classificação final de acesso para esta licenciatura quando comparada com as classificações obtidas no ensino secundário.

> Estamos, assim, a ser triplamente penalizados no DARQ-FCTUC. Primeiramente, por a maioria dos alunos que escolhe a licenciatura em arquitectura da FCTUC não ser colocada em 1aำ opção; em segundo lugar por os nossos alunos estarem melhor preparados para frequentarem a licenciatura em Matemática da FCTUC do que os próprios alunos que foram colocados nesta licenciatura - nem Alberti pediria tanto - e, por último, pelo simples facto de a pintura não ter sido contemplada nas provas de acesso.

> Não é só no DARQ-FCTUC que está sendo colocada em causa a forma de ingresso na licenciatura. No universo de 2612 e 2527 candidatos que concorreram a lugares nas escolas públicas nos anos de 1997 e 1998 e a que corresponde um total de colocados de, respectivamente, 365 e 340, há, também, fortes possibilidades de os potencialmente mais qualificados para frequentarem aqueles cursos nunca o poderem fazer. Como nos lembra o Prof. Joaquim Vieira (1999) da FAUP e da Universidade do Minho, comprova-se que 
"no conjunto de estudantes que frequentaram o primeiro ano da FAUP, com médias mais elevadas da classificação de acesso $(19,6 / 17,7)$ e da licenciatura em Arquitectura da Universidade do Minho, com médias menos elevadas $(18 / 15,4)$, a presença de alunos muito qualificados ser, em termos percentuais, praticamente a mesma nas duas escolas". - É com o objectivo de reduzir, pelo menos parcialmente, a desadequação do regime de ingresso que a Comissão Científica do DARQ aprovou, recentemente, a promoção e a adesão ao estabelecimento de uma Prova Nacional de Ingresso que configura um modelo de acesso à licenciatura em Arquitectura da FCTUC ${ }^{\text {(ver Fig.7) }}$ que pode ser designado, à semelhança dos modelos de desenvolvimentos anteriormente descritos, de Mutatis Mutandis (Mudando o que tem de Ser Mudado) como alternativa ao modelo de acesso existente, o De Jure (De Facto).

> No passado dia 17 de Março teve lugar uma reunião na Universidade do Minho, em Guimarães, para se discutir a forma de ingresso nos cursos de Arquitectura das Universidades Públicas tendo sido proposto, de acordo com o estipulado no Decreto-Lei n²96-A/98, a realização de uma Prova Nacional de Ingresso com o peso de $50 \%$ ficando a restante ponderação afecta às classificações que o aluno traz do ensino secundário.

> Aquela prova tem por objectivo fazer uma avaliação das competências ou capacidades específicas para realizar estudos superiores especializados no domínio da arquitectura.

> Para o efeito, sugere-se que se elabore anualmente, por um jurí nacional, um modelo geral de prova que será concretizada para cada estabelecimento de ensino e terá a forma de desenho à vista ou de imaginação, de elaboração de textos interpretativos de imagens bem como de simulação de contextos projectuais elementares, de especulação compositiva sobre elementos formais dados ou, ainda, de aplicação de sistemas de representação a casos concretos.

> De acordo com o Prof. Joaquim Vieira (1999) a prova não terá de se referir, explicita ou implicitamente, aos programas do ensino secundário, "mas é evidente que não ultrapassará esses contextos temáticos ou de conteúdos. Porém, o que será mais decisivo serão as capacidades de interpretaçăo formal, a maturidade conceptual, a capacidade especulativa, a intencionalidade projectual básica, a sensibilidade plástica e a capacidade perceptiva".

> No entanto, entre a aprovação pelos Conselhos ou Comissões Científicas das escolas públicas que apresentam licenciaturas nos seus curricula e a efectiva implementação por parte do Ministério da Educação da Prova Nacional de Ingresso passará algum tempo onde os desajustes detectados relativos ao ingresso na licenciatura do DARQ-FCTUC continuarão a persistir. $\mathrm{O}$ que fazer entretanto ?

> Lembremos, a este propósito, que Alberti (op. cit.) não sugere que o arquitecto seja "um Zeuxis com os pincéis, um Nicómano com os números ou um Arquimedes para traçar ângulos e linhas. Bastará que domine os elementos pictóricos sobre os quais já dissertei, que tenha adquirido conhecimentos de matemática para aplicações com finalidades práticas nos quais concorrem ângulos, números e linhas, como é o caso dos que nos foram 
legados pela tradição para medir pesos, superfícies e volumes e que alguns designam por espaçamento e modulação."."1)

Em resumo, pensamos que seja adequado, neste momento de transição e enquanto a Prova Nacional de Ingresso não estiver implementada, adoptar o modelo de ingresso da FAUP. Por outro lado, quando aquela Prova for o procedimento de avaliação as disciplinas nucleares, sobre as quais incidirá uma ponderação valorativa relativamente às classificações do ensino secundário, deverão continuar a ser a Matemática ou a Geometria Descritiva cumprindo-se, assim, o acertado desígnio de Alberti de ver a pintura e as matemáticas como disciplinas essenciais e propedêuticas para a formação do arquitecto.

> Por último, mas nem por isso menos importante, gostaria de me referir às condições das instalações físicas existentes no DARQ e que têm levantado, justamente, considerações da mais diversa ordem.

> Temos vivido, desde que nos instalámos no Colégio das Artes, em condições relativamente precárias quando comparadas com as de outros Departamentos mais antigos da Universidade ou que se instalaram, recentemente, no Polo II. Verdade seja dita que foi por decisão, há alguns anos atrás, do Departamento de Arquitectura que ficámos na Alta, por opção e não por imposição, mas com a esperança de que, após o Plano de Reconversão dos Espaços dos Colégios de S. Jerónimo e das Artes, do Laboratório Químico e da área envolvente de autoria do $\operatorname{Arq}^{\circ}$ Gonçalo Byrne, houvesse algum vislumbre sobre a ocupação dos espaços que nos estavam destinados no Colégio de S. Jerónimo. Entretanto, segundo fontes fidedignas, é provável que entre as actuais e as futuras instalações ainda passemos por uma fase intermédia e provisória, o que nos leva a tomar algumas medidas cautelares em relação às actuais instalações começando, para isso, por fazermos um breve diagnóstico da situação presente.

> Em relação aos actuais espaços de ensino do Colégio das Artes a sua ocupação é nos favorável, principalmente quando relacionamos as dimensões das salas de aula de Projecto e Desenho com o número de alunos (ver Tabela 7).

> Para os 267 alunos inscritos no ano lectivo de 1998/99 nas disciplinas de Projecto I a V temos 278 estiradores e nunca a ocupação efectiva das salas de aula, consideradas ano a ano, ultrapassa aquele número de estiradores (E-FI). Isto significa que, em termos práticos, temos, pelo menos, atribuído a cada estudante e de forma cativa um estirador durante todo o ano lectivo. Se considerarmos que os alunos podem utilizar os espaços do Departamento durante 24 horas por dia durante sete dias da semana podemos dizer que temos condições excepcionais de utilização das instalações existentes, porventura dificilmente igualáveis, quer em escolas públicas como privadas nacionais e não exagero quando digo até mesmo em escolas europeias.

> A única discrepância que notámos verificou-se em relação às disciplinas de indole mais teórica que foram deslocadas, neste ano de transição curricular, para os três primeiros anos da licenciatura como é o caso da Geografia, Antropologia do Espaço e Teoria da 
Arquitectura I sem que, excepto no caso da Geografia, tenha ocorrido sobrecarga em relação às instalações físicas disponíveis.

> Em relação aos espaços de apoio para as actividades pedagógicas, nomeadamente em relação aos espaços destinados aos docentes, à Secretaria, à Biblioteca, ao Centro de Estudos, às Salas de Computadores, ao Bar, às Fotocópias, ao NUDA e ao Átrio estão sendo feitos ajustes pontuais, dentro das disponibilidades orçamentais, para efeitos de manutenção, reconversão ou expansão em sintonia com o Novo Plano de Instalações no Colégio das Artes. É de salientar a conjugação de esforços que está a ser feita para arranjarmos financiamento para a instalação de um anfiteatro resultante, por um lado, da transferência de verbas do ano lectivo transacto, destinadas às instalações pedagógicas do DARQ e, por outro, decorrente da negociação que está sendo feita com a Vice-reitoria para que o pagamento dos trabalhos realizados no âmbito do Centro de Estudos consiga cobrir, pelo menos parcialmente, o equipamento necessário ao funcionamento daquele espaço de ensino.

> Neste contexto e na suposição de mudança a médio prazo das actuais instalações somos levados a sugerir uma atitude cautelar, mas não impeditiva, em relação à execução do Novo Plano de Instalaçōes para o Colégio das Artes.

> Para finalizar, dirijo-me especialmente aos alunos que estão colectivamente presentes, pela primeira vez, num Encontro de Tomar ao colocar algumas reflexões finais sobre as convenções e conceitos disciplinares sobre os quais já discorremos bem como ao nomadismo a que nos referimos no início desta comunicação.

> Para isso, gostaria de fazer referência, não mais à inserção institucional do DARQ, mas a uma carta de Le Corbusier de 6 de Outubro de 1953 onde este sugere três regras de comportamento, insuspeitadamente actuais, dirigidas aos arquitectos: a primeira relativa à luta de Dom Quixote contra os moinhos de vento, a segunda à necessidade de arrasar as muralhas de Tróia e a última ao cavalo da tipóia, le cheval de fiacre ${ }^{\text {(ver Fia. B) }}$.

> Comecemos pela última. Le Corbusier sugere que é preciso todos os dias puxarmos a tipóia como sucedeu com os pioneiros do Movimento Moderno, há mais de duas gerações, em resposta à rigidez dos procedimentos e dos interesses consolidados (ver Benévolo, 1994). Por outras palavras, se nos pautarmos por esta sugestão de Le Corbusier "sejamos realistas, peçamos o impossível" (Michel, 1998) no sentido daquilo que os arquitectos fazem poder ser mediador de outras instâncias - nomeadamente das técnicas, das imagens e do panorama cultural de cada momento que passa - e as correspondentes intervenções apresentarem-se disciplinarmente autónomas o que nos permite ter, ainda e apesar de tudo, alguma dose de optimismo nos tempos que correm na medida em que aquelas mediações interpretativas se podem transformar em intervenções instauradoras.

> A segunda sugestão refere-se à necessidade de, para reconquistarmos o controle da forma arquitectónica e da renovação da sua linguagem, termos de ser argutos como Ulisses na guerra de Tróia, ultrapassando, tanto ontem como hoje, barreiras e interesses instalados, 
susceptíveis de gerarem perplexidades diversas, a que fizemos referência no início desta comunicação. Esta é a nossa condição errante e nómada que nos permite expôr, de forma mais ou menos eloquente, propostas credíveis que façam uma mediação, dialética e não submissa, entre as nossas identidades culturais e disciplinares face às diferenças do mundo de hoje.

> A primeira regra, a que resta, refere-se ao combate do arquitecto contra a subjugação às leis do mercado das carteiras de encomendas e às transformações relacionadas com os mecanismos necessários, entre outros, ao licenciamento de obras e ao controle da profissão que fazem com que a arquitectura seja mais entendida como um serviço a ser prestado e menos como proposta de intervenção cultural.

> Todos estes moinhos de vento que se mantêm de pé perante as incertezas das topografias fluidas (ver Morales, 1997) que articulam o terreno movediço onde a produção artística e arquitectónica actual se processa, são uma constante da vida profissional a que a escola somente pode dar uma aproximação crítica. O que é importante é que esta seja colocada ao longo do curso de forma a permitir que ocorra um processo de transformação global de atitude face a estes constrangimentos.

> Como nos lembra o autor de Dom Quixote, assim não tereis “...motivo para andar a mendigar sentenças aos filósofos, conselhos à Divina Escritura, fábulas aos poetas, discursos aos oradores ou milagres aos santos. Só tendes que vos preocupar que as vossas frases saiam simples, com uma linguagem expressiva, sóbria e bem ordenada, harmoniosa e alegre, expressando claramente as vossas ideias e conceitos ... e não será pequena proeza se conseguirdes tal intento" (Cervantes, 1616).

> Assim sejam, tous les jours, as vossas incertas convençốes e as nossas contraditórias ficçöes. 